\title{
Bone Marrow Immunohistochemistry a Valuable Tool in Diagnosing Hodgkin's Lymphoma
}

\author{
Rateesh Sareen $^{1 *}$, Menka Kapil ${ }^{1}$, Vanita Govil², Anjali Sharma ${ }^{3}$ and G N Gupta ${ }^{1}$ \\ ${ }^{1}$ Department of Pathology \& Transfusion Medicine, Santokba Durlabhji Hospital, Jaipur, India \\ ${ }^{2}$ Department of Medicine, Santokba Durlabhji Hospital, Jaipur, India \\ ${ }^{3}$ Department of Pathology \& Transfusion Medicine, Bhagwan Mahaveer Cancer Hospital \& Research Centre, Jaipur, India
}

\begin{abstract}
We describe a case of 40 year male who was diagnosed with Hodgkin's lymphoma by using Immunohistochemistry on bone marrow. The case was a diagnostic challenge as Fine needle aspiration cytology of cervical lymph node showed reactive hyperplasia and the patient didn't consent for lymph node excision biopsy, leaving us with limited options. The presence of few atypical cells in peripheral blood smears examination prompted us to go for bone marrow examination in this case. A subsequent Immunohistochemistry on bone marrow was positive for CD 30 and Pax-5 making the diagnosis of Hodgkins Lymphoma. The case is glaring example of the utility of Immunohistochemistry on bone marrow specially in cases with high index of suspicion like the presence of necrosis, Reed Sternberg cell or it's variant in a polymorphous background or focal fibrosis and myxoid change in bone marrow.
\end{abstract}

Keywords: Hodgkin's Lymphoma, Immunohistochemistry, Bone Marrow

\section{Introduction}

Fine needle aspiration cytology (FNAC) is a popular technique used for the workup of lymph nodes for diagnosis of benign and malignant conditions. It is used as first line diagnostic tool for lymphoma screening and further classification into Hodgkin's and non Hodgkin's type. ${ }^{1}$ The diagnosis of Hodgkin's lymphoma relies on the presence of classical Reed Sternberg / Hodgkin cell in a pleomorphous cellular background. RS cells need to be differentiated from immunoblasts (being smaller and lacking prominent nucleoli) and atypical cells in peripheral T cell lymphoma (PTCL). ${ }^{2,3}$ In the absence of RS cells, large mononuclear cells with prominent nucleoli should raise suspicion of Hodgkin's lymphoma. This prompted us to report the case which posed diagnostic difficulty due to lack of RS cells in cervical lymph node FNAC and patient's refusal of going for excisional biopsy of lymph node.

\section{Case Report}

We present a case of 40 year male smoker with complaints of high grade fever with chills, oral ulcers and vomiting since a week. The patient was diagnosed with ChurgStrauss syndrome two months back and was taking oral steroids \& antihistamics. On examination there was generalized lymphadenopathy, right sided pleural effusion with mild ascites. On admission laboratory examination revealed -hemoglobin $15.3 \mathrm{~g} / \mathrm{dL}$, red blood cell count- 5.30 x $109 / \mathrm{mm} 3$, white blood cell count $25.54 \times 103 / \mathrm{mm} 3$, platelet count $150 \times 109 / \mathrm{mm} 3$. The differential showed Polymorphs- 82\%, Lymphocytes- 5\%, Eosinophils- 10\%,
Monocytes- $1 \%$ \& atypical cells- $02 \%$. The INR was 1.37 and Prothrombin time (PT) 17.3 seconds. Biochemical investigations showed Blood urea nitrogen ( BUN)- 41 $\mathrm{mg} / \mathrm{dl}$, Creatinine $3.6 \mathrm{mg} / \mathrm{dl}$, SGOT- 29 IU, SGPT-39 IU, Total bilirubin- $0.9 \mathrm{mg} / \mathrm{dl}$, LDH- $581 \mathrm{IU}$ \& Alkaline phosphatase 179 IU. The electrolytes were Sodium- 129 $\mathrm{mEq} / \mathrm{L}$, Potassium- $4.9 \mathrm{mEq} / \mathrm{L}$ and chloride $90 \mathrm{mEq} / \mathrm{L}$. Rhuematoid factor -8.9 IU/ml, Serum Magnesium- $3.7 \mathrm{mg} /$ dl, Serum Calcium- 6.2 mg/dl, Complement C3- 68 mg/dl , Complement C4-80 mg/dl and Procalcitonin - 11.93ug/L. The Serum vitamin B12 was 223 pg/L \& Folate $6.91 \mathrm{pg} / \mathrm{L}$. Urine examination showed grade 1 proteinuria, the rest of microscopy was unremarkable.

Patient tested negative for rapid malaria antigen test and non reactive for HIV-1 \& 2, Hepatitis B surface antigen and hepatitis $\mathrm{C}$ antibody. Scrub Typhus IgM was negative. ANA and blood culture were also negative. Ig M antibody to viral capsular antigen to Ebstein Bar Virus (EBV) was positive. The bone marrow examination showed hypercellular marrow with normoblastic erythroid series, myeloid hyperplasia and unremarkable megakaryocytic series.(Fig-1) The biopsy showed pleomorphic population of cells including neutrophils, lymphocytes, eosinophils, plasma cells and occasional large cells with high nucleocytoplasmic ratio having prominent eosinophilic nucleoli having mild to moderate amount of cytoplasm. (Fig-2) The pleomorphic population of cells along with the presence of large cell prompted us to advise immune markers for ascertaining the nature of large cells. There 
was absence of typical Reed Sternberg cells or any of it's variants on light microscopy. On Immunohistochemistry the cells were positive for CD 30 (Fig-3) and pax-5 (Fig-4, dim positive). It was negative for CD 20 (Fig-5) , Fascin (Fig-6), and ALK. The case was diagnosed as Hodgkin's lymphoma

\section{Discussion}

FNA has an important role in the management of Hodgkin's disease in the primary diagnosis, staging and detection of residual \& recurrent disease ever since Guthrie reported his experience in the diagnosis of Hodgkin's disease by 'gland puncture' in $1921 .{ }^{4}$ The wide range of display of varying histology and cytology in Hodgkin's disease ranging from

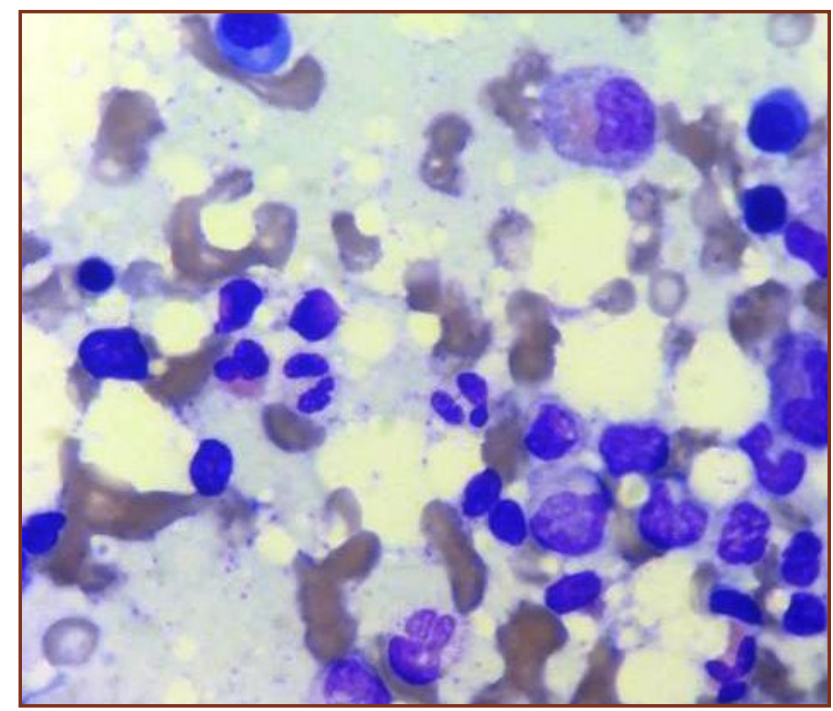

Fig. 1: Bone Marrow aspiration (Leishman stain, 100x oil immersion).

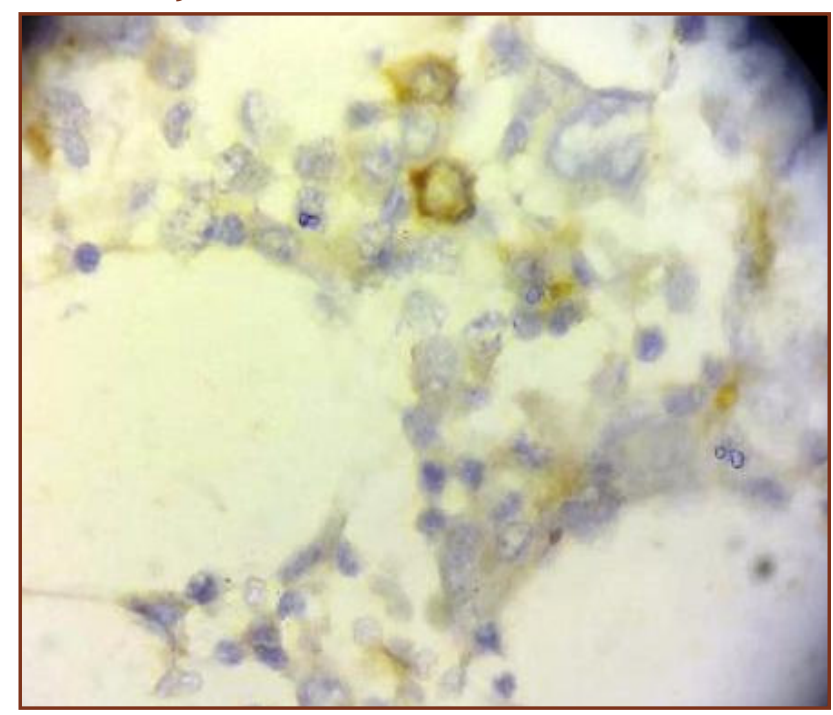

Fig.3: CD 30 Immunohistochemistry ( $40 \mathrm{x})$. benign to malignant process poses a diagnostic dilemma especially in absence of Reed Sternberg (RS) cells in aspiration smears. There are times when the lymph nodes are matted and sampling from such uninvolved lymph nodes show reactive hyperplasia and / or granulomatous inflammation. Without the presence of RS cells these cases require multiple aspirations from different areas of lymph node. ${ }^{5,6}$

The case presented diagnostic problem as FNA revealed reactive hyperplasia only. The strong clinical suspicion of lymphoma prompted the clinician to go for excisonal biopsy which was subsequently not consented by the patient. Finally we decided to go for bone marrow examination of the patient for which the patient gave

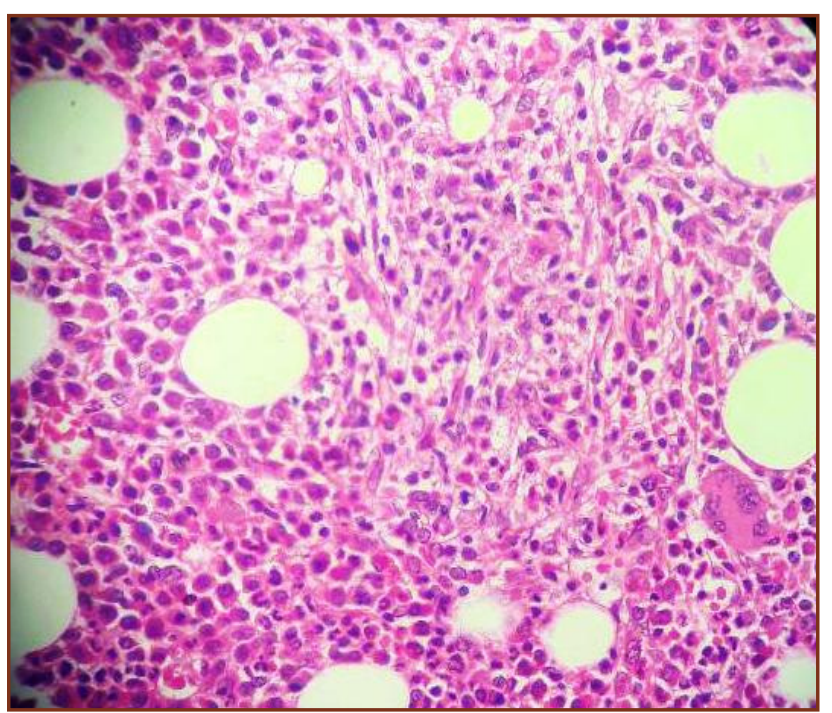

Fig. 2: Bone Marrow Biopsy (Hematoxylin \& Eosin, 40 x).

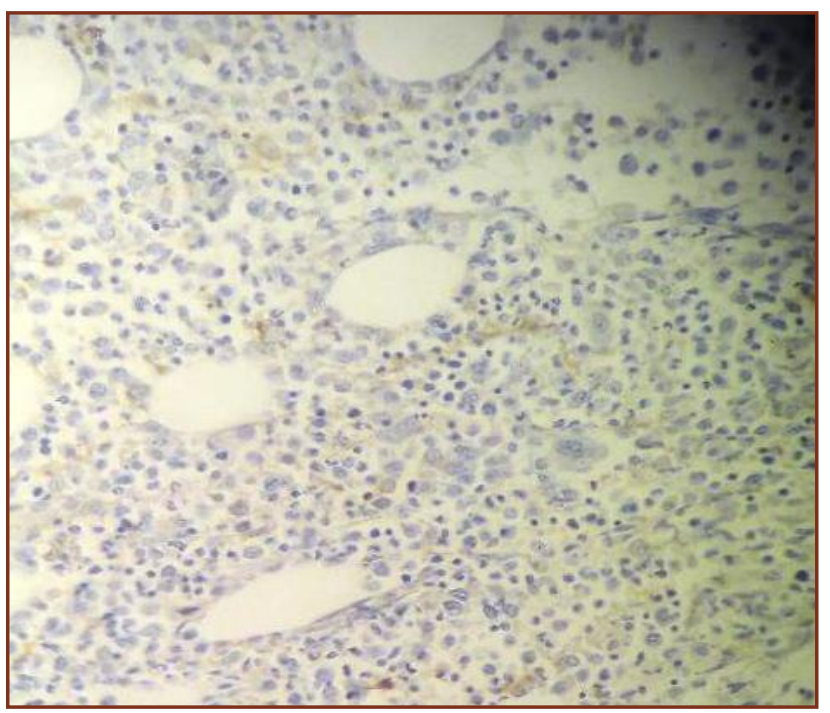

Fig. 4: Pax Immunohistochemistry ( $40 \mathrm{x}$ ). 


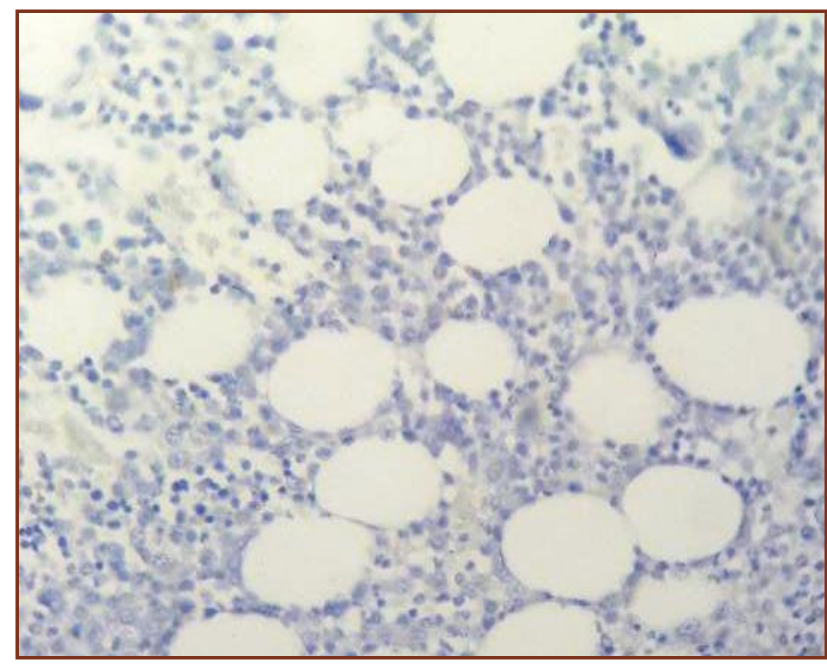

Fig. 5: CD 20 Immunohistochemistry ( $40 \mathrm{x}$ ).

consent. The bone marrow aspiration showed myeloid hyperplasia and normal erythroid \& megakaryocytic lineages. The bone marrow biopsy showed pleomorphic cell population with large atypical cells having prominent eosinophilic nucleoli. There was absence of typical RS cell or any of its variants. To ascertain the nature of atypical cells Immunohistochemistry was done which proved it to be Hodgkin's lymphoma.

The case highlights the multidisciplinary clinic pathological approach in clinching the diagnosis. The EBV positivity did not refrain the diagnostic team from settling with the infectious etiology rather prompted us to thoroughly search for etiology behind lymphadenopathy and reaching the diagnosis.

\section{Conclusion}

The pathologist should be aware of limitations of FNA and suspicion of Hodgkin's lymphoma ${ }^{7}$ when the patient presents with unexplained lymphadenopathy and atypical large cells in polymorphous inflammatory background in patients with non diagnostic specimens a close follow up is required.

\section{Acknowledgements}

MUDIT SHARMA Senior Technician, Immunohistochemistry laboratory, Bhagwan Mahaveer Cnacer Hospital \& Research Center, Jaipur.

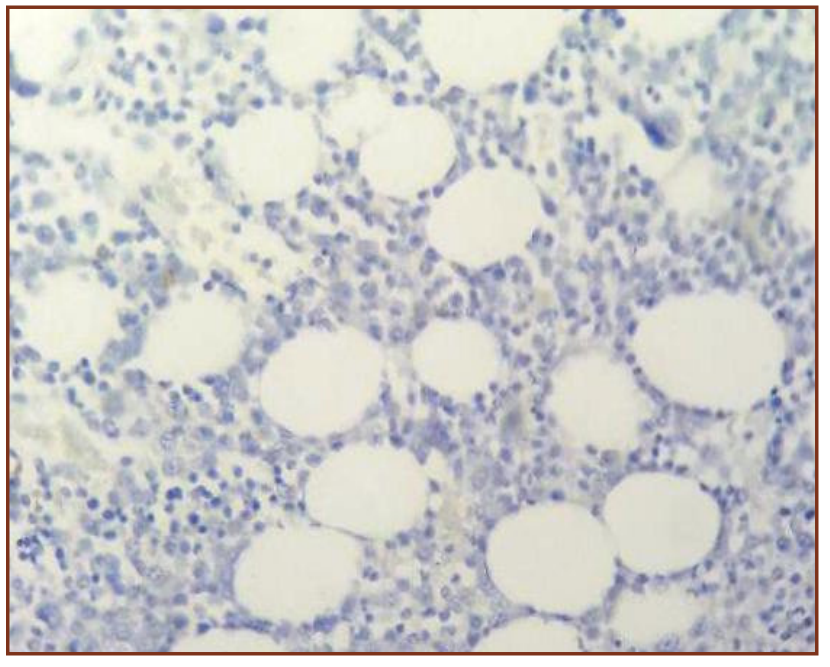

Fig. 6: Fascin Immunohistochemistry ( $40 \mathrm{x})$.

\section{Reference}

1. Chhieng DC, Cangiarella JF, Symmans WF, Cohen JM. Fine needle aspiration cytology of Hodgkin disease: a study of 89 cases with emphasis on the false-negative cases. Cancer Cytopathol 2001;93:52-9

2. Demay RM. The art and science of cytopathology. Vol II. ASCP: Chicago, IL; 1996. p. 779-846

3. Mathur S, Verma K. Peripheral T-cell lymphoma not otherwise specified vs. Hodgkin's lymphoma on fine needle aspiration cytology. Acta Cytol 2005;49:373-7

4. Friedman M, Kim U, Shimaoka K, Pahahon A, Han T, Stutzman L. Appraisal of aspiration cytology in management of Hodgkin's disease. Cancer 1980; 45: 1653-63.

5. Kranse DL, Naritoku WY, Cosgrove MM. Diagnosis of syncytial (lacunar cell-predominant) nodular sclerosing Hodgkin's disease by fine needle aspiration-a case report. Acta Cytol 1993; 37: 418-22.

6. Warnke RA, Weiss LM, Chan JK, Cleary ML, Dorfmen RF. Atlas of tumor pathology: tumors of the lymph nodes and spleen. 3rd series. Washington DC: AFIP, 1995.

7. Steel BL, Scwartz MR, Ramzy I. Fine needle aspiration biopsy in the diagnosis of lymphadenopathy in 1,103 patients: role, limitations and analysis of diagnostic pitfalls. Acta Cytol 1995; 39:76-81.

*Corresponding author:

Dr Rateesh Sareen, D.N.B Pathology, Department of Pathology \& Transfusion Medicine, Santokba Durlabhji Hospital, Jaipur, India

Phone: +91 01412566251

Email: drrateeshsareen@yahoo.co.in.

Financial or other Competing Interests: None. 